\title{
Improvement of Surgery of Pancreatic Head Masses
}

\author{
DOI: $10.17691 / \mathrm{stm} 2017.9 .2 .20$
}

Received December 10, 2015

\author{
G.M. Barvanyan, MD, PhD, Head of Surgery Department
}

Komi Republic Hospital, 114/2 Pushkin St., Syktyvkar, Komi Republic, 167004, Russian Federation

The aim of the investigation was to improve the results of pancreatoduodenectomy by applying the algorithm of choice of pancreatodigestive anastomosis (PDA) and two original techniques for pancreatojejunal anastomosis.

Materials and Methods. When developing an algorithm to choose PDA we took into consideration the complication risk factors: pancreatic tissue consistency, pancreatic duct diameter, and the conformity of pancreatic and jejunal slice plane sizes. Based on the combination of these factors we distinguished five degrees of preparedness to anastomosis, and determined the optimal degrees for every PDA. Within the framework of the algorithm we used two pancreatojejunal anastomosis techniques: invaginated end-to-end with through U-shaped sutures and end-to-loop with pancreatic stump invagination into an enteric reservoir. Five PDA types were used in 48 patients of the main group, and end-to-end pancreatojejunal anastomosis were used in 52 cases in 58 subjects of the control group.

Results. Both groups were comparable by the main complication risk factors: pancreatic tissue consistency and a pancreatic duct diameter. The incidence of PDA dehiscence was 4 cases in the treatment group, and 10 cases in the control group. Neither acute pancreatitis nor lethal outcomes due to technical features of PDA formation were found in the treatment group. In the comparison group there were 6 cases of acute pancreatitis and 3 fatal cases. An original end-to-end pancreatojejunal anastomosis was used according to the algorithm in 10 patients, and end-to-loop - in 14 patients of the treatment group. The developed algorithm enables to choose an optimal way of anastomosis formation depending on morphometric characteristics of anastomosed pancreatic and jejunal stump.

Conclusion. A customized approach to PDA selection and the original techniques of anastomosis formation within the framework of the algorithm enable to reduce the number of severe complications and fatal cases after pancreatoduodenectomy.

Key words: pancreatodigestive anastomoses; algorithm of pancreatodigestive anastomosis; end-to-end pancreatojejunal anastomosis; end-to-loop pancreatojejunal anastomosis; pancreatoduodenectomy.

Pancreatoduodenectomy is the only way for radical surgery of pancreatic cancer. Over the last decades the mortality rate after pancreatoduodenectomy was managed to have decrease up to $0-2 \%[1,2]$. However, the complication rate has no reducing trend tendency and still remains at the level of $27-54 \%$ [2-4]. The most frequent complication after pancreatoduodenectomy is pancreatodigestive anastomosis (PDA) dehiscence, which develops in $9-14 \%$ cases $[3,5]$. In its turn, PDA dehiscence is the main cause of life-threatening complications and fatal cases [6-10]. To reduce the anastomosis dehiscence rate and, correspondingly, improve pancreatoduodenectomy results, a lot of PDA techniques have been suggested, and they are frequently considered universal. However, the possibility of applying one PDA method in all cases is problematic due to pancreatic stump condition variability and anatomic features of the anastomosed jejunum or stomach [11, 12]. Therefore, an individualized approach to anastomosis formation is relevant in the context of reducing $P D A$ dehiscence.

The aim of the investigation was to improve the results of pancreatoduodenectomy by applying the algorithm of choice of pancreatodigestive anastomosis and two original techniques for pancreatojejunal anastomosis.
Materials and Methods. PDA selection algorithm is based on three risk factors of developing complication specific for pancreatojejunal anastomosis (PJA): pancreatic stump tissue condition, pancreatic duct diameter, and the size conformity of pancreatic stump slice plane and anastomized jejunal loop [13]. The pancreatic tissue condition was determined as dense (D) or soft (S) by a criterion of "pancreatic tissues cut by ligature". The cases, when tiring a knot, the thread did not cut the pancreatic tissue were considered $D$ type, and if thread cut the pancreatic tissue the cases were thought as $M$ types. Possible pancreatic duct diameter could be of two types: if the duct diameter was $3 \mathrm{~mm}$ and more, it was marked by figure 1 ; if the diameter was less than $3 \mathrm{~mm}$ - by figure 2. Pancreatic duct stenting was considered possible only if the duct diameter was $3 \mathrm{~mm}$ and more. In a diameter less than $3 \mathrm{~mm}$ a duct had a stent for a period of pancreatic stump homeostasis and PDA performance. A plus sign ("+") is added to the pancreatic type (D) and the duct diameter if the pancreas is dense, and a jejunal lumen size is larger than the pancreatic stump resection plane. The minus sign ("-") is added if the sizes are equal, or the jejunal lumen is smaller. Based on the combination of the mentioned factors, five degrees of pancreatic stump readiness for anastomosis and PDA optimal for each degree were

For contacts: Georgy M. Barvanyan, e-mail: bgmee07@yandex.ru 
Table 1

Choice of a technique for pancreatodigestive anastomosis

\begin{tabular}{ccl}
\hline $\begin{array}{c}\text { Pancreatic stump } \\
\text { readiness degree }\end{array}$ & $\begin{array}{c}\text { PDA choice factor } \\
\text { combination }\end{array}$ & \multicolumn{1}{c}{ PDA types } \\
\hline I & D1+ & All PDA types \\
\hline II & D2+ & End-to-end, end-to-side, end-to-loop IPJA and IPGA \\
\hline III & D1- & $\begin{array}{l}\text { End-to-loop IPJA and IPGA } \\
\text { End-to-side and end-to-loop PJA with separate pancreatic duct } \\
\text { stitching and PGA with separate pancreatic duct stitching }\end{array}$ \\
\hline IV & S1 & $\begin{array}{l}\text { End-to-loop IPJA and IPGA } \\
\text { End-to-loop PJA with separate pancreatic duct stitching and PGA } \\
\text { with separate pancreatic duct stitching }\end{array}$ \\
\hline V & D2-, S2 & End-to-loop IPJA and IPGA \\
\hline
\end{tabular}

Note. IPJA and IPGA are invaginated pancreatojejunal anastomoses and pancreatogastric anastomoses; PJA is pancreatojejunal anastomosis; PGA is pancreatogastric anastomosis. The anastomoses with the entire pancreatic resection surface being stitched in the lumen of the intestine or stomach were referred to invaginated pancreatodigestive anastomoses (PDA).

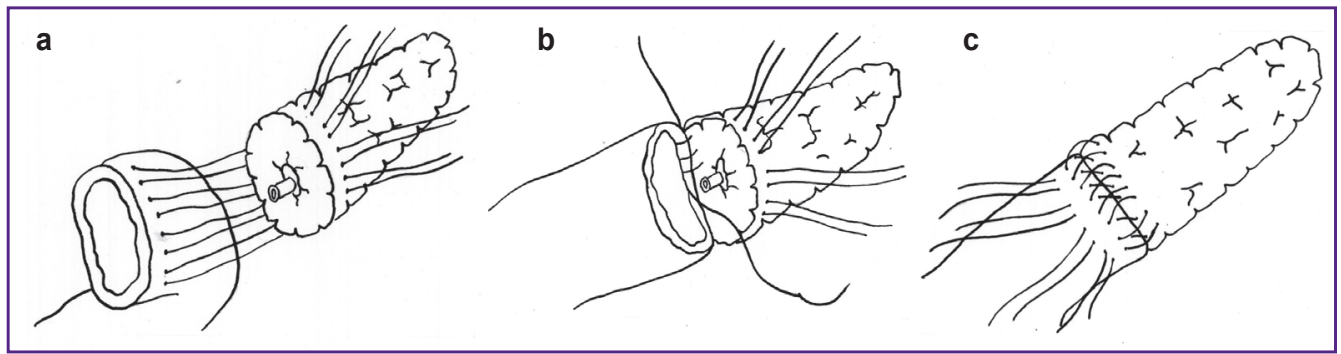

Figure 1. A technique to form an end-to-end invaginated pancreatojejunal anastomosis:

(a) U-shaped sutures put through the pancreatic parenchyma; (b) an internal row of anastomosis formed by putting a continuous suture; (c) U-shaped sutures put on the anterior wall

distinguished (Table 1). PDA selection algorithm has been used since 2007.

Two original PJA techniques are applied within the algorithm framework: end-to-end and end-to-loop. End-to-end invaginated pancreatojejunal anastomosis (IPJA) (RF patent for invention 2432126 dated January $11,2010)$ is made as follows [14]. The Wirsung duct is stented by a catheter. Four or five U-shaped seromuscular monofilament sutures are put on the posterior jejunal wall, parallel to the lumen, $1.5-2 \mathrm{~cm}$ away from the jejunal border. Both threads of each suture are put through the pancreatic parenchyma (Figure 1 (a)). An internal continuous stitch is put between the intestinal lumen and the pancreatic resection surface (Figure 1 (b)). The threads of the previously put U-shaped stitch are used for seromuscular sutures on the anterior jejunal surface, perpendicular, $1 \mathrm{~cm}$ away from the continuous suture edge (Figure 1 (c)). The pancreatic stump is invaginated in the jejunal lumen and the stitches are tied. Lateral anastomosis walls are strengthened by an interrupted stitch.
The second technique is an end-to-loop reservoir IPJA (RF patent for invention 2552670 dated April 22, 2014) used in any degree of pancreatic stump readiness for anastomosis. For this type anastomosis, a free end of the jejunum is folded in a form of a double-barreled shotgun, $6-8 \mathrm{~cm}$ in length. A 3-cm longitudinal incision is made on the antimesenteric border of a double-barreled shotgun. Jaws of the linear stapler are put through the formed hole in both bends of the double-barreled gun (Figure 2 (a)) forming an enteric reservoir. If necessary, the incision on the intestinal reservoir can be lengthened to coincide with the pancreatic stump diameter. The first row of interrupted stitches is put between the pancreas and the posterior wall of the intestinal reservoir, 1.0$1.5 \mathrm{~cm}$ distally from the pancreatic resection border. An internal continuous suture is put between the lumen and pancreatic section perimeter. The second row of interrupted stitches is made between the pancreas and the anterior wall of the intestinal reservoir, $1.0-1.5 \mathrm{~cm}$ away from the internal suture row (Figure 2 (b)). After making a longitudinal section of the intestine, there 


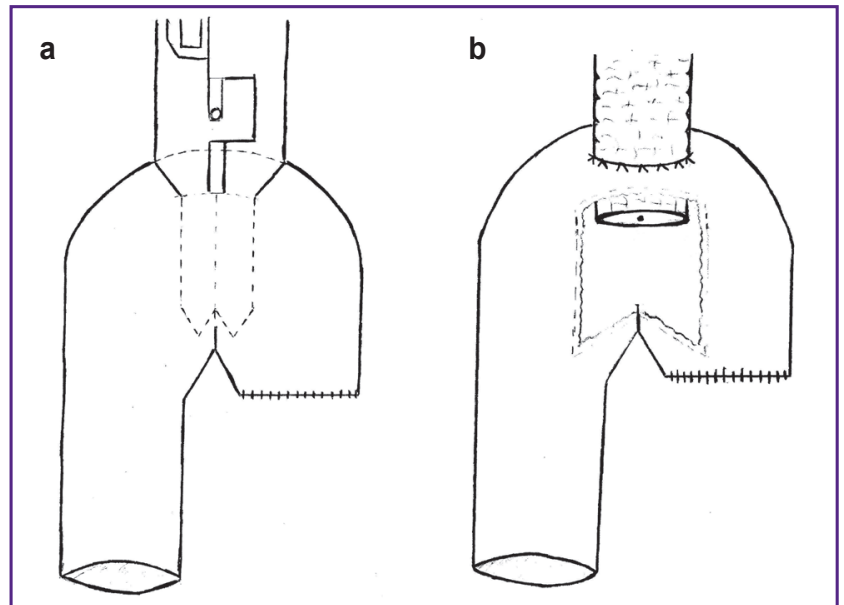

Figure 2. A technique to form an end-to-loop invaginated pancreatojejunal anastomosis:

(a) the formation of enteric reservoir by a linear stapler; (b) the appearance of pancreatic stump invaginated into the enteric reservoir

can be wall abundance in the staple suture area, which evaginates from the reservoir and prevents from forming the anastomotic anterior lip. In this case it will be sufficient to trim it for better adaptation of the pancreas and intestinal wall.

106 pancreatoduodenectomy were performed from 2004 to 2014 in the surgical departments of Komi Republic Hospital and Komi Republic Oncology Dispensary (Syktyvkar). The patients were divided into two groups. The study group involved 48 patients (22 females and 26 males) with PDA performed according to a suggested algorithm. A comparison group consisted of 58 patients (24 females and 34 males). Mean age of the study group patients was $54.5 \pm 9.2$ years (from 35 to 80 years), in the comparison group mean age was $55.1 \pm 8.7$ years (from 30 to 76 years).

The study was carried out in accordance with the Declaration of Helsinki (adopted in June 1964, Helsinki, Finland and revised in October 2000, Edinburgh, Scotland) and was approved by the Ethics Committee of Komi Republic Hospital. All female patients gave their written informed consent.

An original end-to-end IPJA has been used in both groups since 2005 . Within the framework of the algorithm the method was applied in degree I of pancreatic stump readiness for anastomosis. An original end-to-

Table 2

Table 3 loop IPJA has been used since 2012, and in the study group only. To prevent postoperative pancreatitis, we administered octreotide, $0.3 \mathrm{mg} /$ day, within 3-5 days.

There was carried out a comparative analysis of pancreatic stump morphometric parameters and complications directly related to PDA technique. Destructive pancreatitis (DP) and/or anastomotic dehiscence were referred to such complications. Postoperative DP was diagnosed by CT or abdominal $\mathrm{MRI}$ and/or the following relaparotomy. PDA dehiscence was determined in accordance with the criteria suggested by Strasberg [15]. According to these criteria, PDA dehiscence is considered to be the amount of drainage discharge, which is over $50 \mathrm{ml}$ a day, and the increase of amylase activity level in the obtained fluid by over 3 times compared to the upper normal amylase level in blood serum since the tenth postoperative day.

To analyze statistical significance of the differences between the groups and the signs in groups considering the number of objects by each sign, we used nonparametric methods: Mann-Whitney tests and $x^{2}$ test with Yates' correction, and Fischer's exact test. The differences were considered significant if $p<0.05$.

Results. Table 2 shows the morphometric data on pancreatic stump in the patients' groups.

Table 3 shows the degrees of pancreatic stump

\section{Morphometric parameters of pancreatic stump}

\begin{tabular}{lccc}
\hline \multicolumn{1}{c}{ Parameters } & $\begin{array}{c}\text { Study group } \\
(\mathrm{n}=48)\end{array}$ & $\begin{array}{c}\text { Comparison group } \\
(\mathrm{n}=58)\end{array}$ & $\mathrm{p}$ \\
\hline $\begin{array}{l}\text { Pancreatic stump tissue (abs. number): } \\
\quad \text { dense }\end{array}$ & 38 & 46 & \\
$\quad$ soft & 10 & 12 & 0.82 \\
\hline $\begin{array}{l}\text { Pancreatic duct diameter is under } 3 \mathrm{~mm} \\
\text { (abs. number/\%) }\end{array}$ & $17 / 35.4$ & $17 / 29.3$ & 0.64 \\
\hline \begin{tabular}{l} 
Stented pancreatic duct (abs. number/\%) \\
\hline
\end{tabular} & $25 / 52.1$ & $52 / 89.7$ & 0.001 \\
\hline
\end{tabular}

Pancreatodigestive anastomoses (PDA) made in the study group according to the developed algorithm

\begin{tabular}{|c|c|c|}
\hline $\begin{array}{c}\text { Pancreatic } \\
\text { stump readiness } \\
\text { degree }\end{array}$ & $\begin{array}{l}\text { PDA type } \\
\text { factor } \\
\text { combination }\end{array}$ & PDA type \\
\hline I & $\mathrm{D} 1+$ & $\begin{array}{l}\text { End-to-end IPJA }(n=17) \\
\text { End-to-side PJA with separate pancreatic duct stitching }(n=1)\end{array}$ \\
\hline ॥ & $\mathrm{D} 2+$ & $\begin{array}{l}\text { End-to-end IPJA }(n=5) \\
\text { End-to-side IPJA }(n=1)\end{array}$ \\
\hline III & D1- & $\begin{array}{l}\text { End-to-loop IPJA ( } n=7) \\
\text { End-to-side PJA with separate pancreatic duct stitching }(n=5)\end{array}$ \\
\hline IV & S1 & End-to-loop PJA with separate pancreatic duct stitching $(n=1)$ \\
\hline V & $\mathrm{D} 2-, \mathrm{S} 2$ & End-to-loop IPJA $(n=11)$ \\
\hline
\end{tabular}

Note. IPJA is invaginated pancreatojejunal anastomoses; PJA is pancreatojejunal anastomosis. 
Table 4

Complications and mortality rate after pancreatodigestive anastomosis (abs. number/\%)

\begin{tabular}{lccc}
\hline \multicolumn{1}{c}{ Complications and mortality } & Study group $(\mathrm{n}=48)$ & Comparison group $(\mathrm{n}=58)$ & $\mathrm{p}$ \\
\hline Postoperative destructive pancreatitis & $1\left(0^{*}\right)$ & $6\left(6^{*}\right) / 10.4$ & 0.98 \\
\hline Anastomotic dehiscence & $5\left(4^{*}\right) / 10.4$ & $10\left(10^{*}\right) / 17.2$ & 0.47 \\
\hline Complications, total & $24 / 50.0$ & $32 / 55.2$ & 0.74 \\
\hline Fatal cases & $3\left(0^{*}\right) / 6.3$ & $11\left(3^{*}\right) / 18.9$ & 0.99 \\
\hline
\end{tabular}

* Complicated and fatal cases due to technical features of anastomoses.

readiness for anastomosis according to the suggested classification and PDA types used in the study group.

The study group had 14 end-to-loop and 10 endto-end IPJA according to the original technique. In the comparison group for PDA we applied the following techniques: end-to-end IPJA in 52 cases $(89.7 \%)$, among them $14(26.9 \%)$ were performed according to the original technique; and end-to-side PJA with separate suture of the pancreatic duct - in 2 cases; invaginated pancreatogastric anastomoses (IPGA) - in 4 cases.

Table 4 shows the complication rate immediately after the surgery and the mortality rate.

In both groups, if destructive pancreatitis developed, Wirsung duct was stented. Isolated PJA dehiscence in the study group was found in 4 patients: S2 with original end-to-loop IPJA - 2 cases; D2+ with original end-toend IPJA (stented pancreatic duct) -1 case; $\mathrm{S} 1-1$ case. Fistulas were closed by themselves $6-10$ weeks later.

Three fatal cases in the study group were not directly associated with PDA. In one patient (D2+, original endto-end IPJA) the splenic artery was injured during lymph node dissection. Relaparotomy revealed the necrosis of the entire pancreatic stump, parapancreatic and the left retroperitoneal cellular tissue, IPJA dehiscence, abdominal effusion contaminated with intestinal content. The splenic artery injury and standard gastric surgical release intending to disintegrate collateral blood flow resulted in pancreatic stump necrosis and IPJA dehiscence development. On the first postoperative day two other patients (D2+, original end-to-end IPJA; S2, end-to-loop IPJA with circular resection of the portal vein) passed away of acute heart failure and intraabdominal hemorrhage against the background of DIC syndrome.

Isolated PDA dehiscence (6 cases) in the comparison group was revealed after end-to-end IPJA, 2 of them were performed according to the original technique. In addition, pancreatic soft tissue was diagnosed in 5 patients. Pancreatic duct was stented in 5 of 6 cases of PDA dehiscence including 4 patients with pancreatic soft tissue. In 4 of 6 patients with DP in the comparison group were found to have PDA dehiscence, and 2 patients died of endogenous intoxication in the early postoperative period, before probable anastomosis dehiscence could develop. DP in these patients developed after end-toend IPJA (5 cases) and end-to-side PJA with separate suture of the pancreatic duct (1 case). The pancreatic soft tissue was revealed in 2 DP patients. 3 patients of 11 died of DP. Other death causes were not directly linked to PDA technique: intra-abdominal hemorrhage (4 cases), acute gastric ulcer perforation (1 case), gastrointestinal hemorrhage with developing gastrojejunal anastomosis (1 case), gastrostasis with irreversible electrolyte disorders (1 case), acute hepatorenal failure (1 case).

Discussion. Pancreatic stump tissue condition and pancreatic duct diameter are considered to be the most significant risk factors of PDA dehiscence [16-18]. To reduce PDA dehiscence rate, the authors [6, 19-21] suggest an individual approach to anastomosis, which is determined, primarily, by the pancreatic condition and pancreatic duct diameter. Currently, there is no lifetime morphometric assessment of pancreatic parenchyma. In literature one can find just a few reports on the criteria to estimate the pancreatic condition. So, Suzuki et al. [21] have determined the pancreatic parenchyma condition (dense or soft) based on the difficulty or easiness in pancreatic tissue dissection by an ultrasound scalpel. We have suggested a criterion of "ligature incision of tissue". Despite the subjectivity of the criterion - dependence on surgeon's individual perception (efforts made, a technique of suture tying) the objectivization is achieved by the following: after determining the pancreatic tissue condition, a surgeon selects PDA, which appears to him to be optimal. Not infrequently, the obviousness of choice is seen when performing hemostasis along the pancreatic stump resection plane by suturing the bleeding areas. If the pancreatic tissue is cut by ligature, a surgeon narrows down a range of possible PDA. So, in pancreatic soft tissue, only end-to-loop IPJA and IPGA are considered to be indicated. The reliability of invaginated PDA is achieved by a wide peritonized anastomosis area due to the enlarged contact area of the intestinal or gastric wall and the pancreatic stump surface. The suggested original end-to-loop IPJA enables to anastomose in any jejunal diameter. The compatibility of diameters of 
the bases forming the anastomosis is adjusted by the longitudinal intestinal section length. The position of the invaginated stump in the lumen of the formed enteric reservoir excludes the pancreatic stump compression by the intestinal wall contributing to a free flow of the pancreatic secretion. The findings prove the feasibility of invaginated end-to-loop PDA in soft pancreas. No DP was revealed in the study group patients with soft pancreas.

Pancreatic duct diameter is significant when selecting PDA. If the diameter is less than $3 \mathrm{~mm}$, PDA with isolated pancreatic duct suturing is unreasonable. No stenting is performed in such a diameter, since the duct sectional area is smaller due to a catheter wall. Moreover, in cases with preserved pancreatic function, it is entirely possible that the pancreatic secretion outflow will be impeded [22]. Two patients in the study group developed subcapsular edema of the pancreatic stump after temporary stenting of the pancreatic duct at the end of the surgery. When the stents were removed, pancreatic secretion was discharged from the pancreatic duct. Persisting subcapsular edema after PDA is thought to be a predictor of DP [23]. 6 patients in the comparison group with the stented pancreatic duct developed DP after surgery.

In the suggested algorithm, in case of the soft pancreas, we do not indicate the correlation of the lumen size and the pancreatic stump resection plane diameter, since the pancreatic stump condition S1 is very rare. In our study there was only 1 case (in the study group) with pancreatic tissue cut by ligature, the pancreatic duct diameter being over $3 \mathrm{~mm}$. The patient was operated on for major duodenal papilla cancer, 6 weeks after pancreatitis. During the operation, 3 small (up to $2 \mathrm{~cm}$ ) abscesses with sequesters in the parapancreatic cellular tissue were tapped. The pancreas inflamed after percutaneous transhepatic transpapillary externalinternal drainage carried out for the biliary tract decompression.

The pancreatic stump resection surface size matching the diameter of the anastomized jejunum is a key condition when choosing PDA. As well as other authors [12] we suppose that a pancreatic stump size and jejunal diameter can be a limiting factor when applying some PDA types. Primarily, it is related to the compression danger of the invaginated pancreatic stump and the pancreatic duct by the intestinal wall in cases when the pancreatic stump diameter is at the incision level or exceeds the intestinal diameter. One of the causes of 2 DP in the comparison group was mistaken end-toend IPJA, when the diameters of the jejunum and the pancreatic stump were equal.

After an original end-to-end IPJA there were revealed 3 cases of isolated dehiscence: 1 - in the study group; 2 - in the comparison group, among them 1 - in soft pancreas. DP with fatal outcome after an original endto-end IPJA developed in 1 patient of the study group, and was not associated with PDA features. An end- to-loop IPJA was used in the study group only, there were observed 2 cases of anastomotic dehiscence in soft pancreas. We consider the absence of DP and independent closure of fistulas during the conservative therapy to be an acceptable outcome for unfavorable PDA conditions. There is no direct association of one fatal case after an original end-to-loop IPJA with the anastomosis.

According to the suggested algorithm, an original end-to-loop IPJA matches all readiness degrees of the pancreas. However, it is not used in cases when a technically easier alternative is available. It is due to the fact that when a reservoir is formed, there can appear an ischemic strip of the intestinal wall in the junction of a staple suture, near the intestinal loop curve, up to 2-3 cm in length and up to $0.5-1 \mathrm{~cm}$ wide. However, the problem can be easily solved by putting seroserous sutures. In addition, an obligatory condition for this type of anastomosis is an available linear stapler (NZKA, GIA and analogues), since the hand formation of enteric reservoir will make the supposed anastomosis unreasonably bulky.

There were no significant differences by isolated PDA dehiscence found in the groups $(p=0.95)$. However, the study group patients had no DP and fatal cases directly related to PDA features.

Conclusion. The suggested algorithm, which includes adapted original IPJA, enables to choose an optimal technique for anastomosis depending on morphometric characteristics of an anastomosed pancreatic stump and jejunum, and improve pancreatoduodenectomy results. A differential approach to pancreatojejunal anastomosis selection enables to reduce the number of destructive pancreatitis cases, which is the main cause of developing life-threatening complications and lethal cases after pancreatectomy.

Study Funding and Conflicts of Interest. The study was not funded by any sources, and the authors have no conflicts of interest related to the present study.

\section{References}

1. Orr R.K. Outcomes in pancreatic cancer surgery. Surg Clin North Am 2010; 90(2): 219-234, https://doi.org/10.1016/j. suc.2009.12.007.

2. Walters D.M., McGarey P., LaPar D.J., Strong A., Good E., Adams R.B., Bauer T.W. A 6-day clinical pathway after a pancreaticoduodenectomy is feasible, safe and efficient. HPB 2013; 15(9): 668-673, https://doi.org/10.1111/hpb.12016.

3. Addeo P., Delpero J.R., Paye F., Oussoultzoglou E., Fuchshuber P.R., Sauvanet A., Sa Cunha A., Le Treut Y.P., Adham M., Mabrut J.Y., Chiche L., Bachellier P. Pancreatic fistula after a pancreaticoduodenectomy for ductal adenocarcinoma and its association with morbidity: a multicentre study of the French Surgical Association. HPB 2014; 16(1): 46-55, https://doi.org/10.1111/hpb.12063.

4. Grobmyer S.R., Pieracci F.M., Allen P.J., Brennan M.F., Jaques D.P. Defining morbidity after pancreaticoduodenectomy: use of a prospective complication 
grading system. J Am Coll Surg 2007; 204(3): 356-364, https:// doi.org/10.1016/j.jamcollsurg.2006.11.017.

5. Fernández-del Castillo C., Morales-Oyarvide V., McGrath D., Wargo J.A., Ferrone C.R., Thayer S.P., Lillemoe K.D., Warshaw A.L. Evolution of the Whipple procedure at the Massachusetts General Hospital. Surgery 2012; 152(3 Suppl 1): S56-S63, https://doi.org/10.1016/j.surg.2012.05.022.

6. Shchastnyy A.T. Postoperative complications of proximal pancreatectomy in patients with chronic pancreatitis. Novosti khirurgii 2011; 19(3): 30-43.

7. Callery M.P., Pratt W.B., Vollmer C.M. Jr. Prevention and management of pancreatic fistula. J Gastrointest Surg 2009; 13(1): 163-173, https://doi.org/10.1007/s11605-008-0534-7.

8. Hong T.H., Youn Y.C., You Y.K., Kim D.G. An easy and secure pancreaticogastrostomy after pancreaticoduodenectomy: transpancreatic suture with a buttress method through an anterior gastrotomy. J Korean Surg Soc 2011; 81(5): 332-338, https://doi.org/10.4174/jkss.2011.81.5.332.

9. Lai E.C., Lau S.H., Lau W.Y. Measures to prevent pancreatic fistula after pancreatoduodenectomy: a comprehensive review. Arch Surg 2009; 144(11): 1074-1080, https://doi.org/10.1001/archsurg.2009.193.

10. Pecorelli N., Balzano G., Capretti G., Zerbi A., Di Carlo V., Braga M. Effect of surgeon volume on outcome following pancreaticoduodenectomy in a high-volume hospital. J Gastrointest Surg 2012; 16(3): 518-523, https://doi. org/10.1007/s11605-011-1777-2.

11. Patyutko Yu.I., Kotel'nikov A.G. Khirurgiya raka organov biliopankreatoduodenal'noy zony [Cancer surgery of the organs of biliopancreatoduodenal area]. Moscow: Meditsina; 2007; 448 p.

12. Zhang B., Xu J., Liu C., Long J., Liu L., Xu Y., Wu C., Luo G., Ni Q., Li M., Yu X. Application of "papillary-like main pancreatic duct invaginated" pancreaticojejunostomy for normal soft pancreas cases. Sci Rep 2013; 3: 2068, https://doi. org/10.1038/srep02068.

13. Barvanyan G.M. Choice of the way of pancreaticodigestive fistula in pancreaticoduodenal resection. Vestnik khirurgii im. I.I. Grekova 2014; 173(6): 27-30.

14. Barvanian G.M. The method of pancreaticojejunostomy in pancreaticoduodenectomy. Khirurgiya. Zhurnal im. N.I. Pirogova 2014; 8: 28-31.
15. Strasberg S.M., Linehan D.C., Clavien P.A., Barkun J.S. Proposal for definition and severity grading of pancreatic anastomosis failure and pancreatic occlusion failure. Surgery 2007; 141(4): 420-426, https://doi.org/10.1016/j. surg.2006.12.001.

16. Inchauste S.M., Lanier B.J., Libutti S.K., Phan G.Q., Nilubol N., Steinberg S.M., Kebebew E., Hughes M.S. Rate of clinically significant postoperative pancreatic fistula in pancreatic neuroendocrine tumors. World J Surg 2012; 36(7): 1517-1526, https://doi.org/10.1007/s00268-012-1598-9.

17. Katsaragakis S., Larentzakis A., Panousopoulos S.G., Toutouzas K.G., Theodorou D., Stergiopoulos S., Androulakis G. A new pancreaticojejunostomy technique: a battle against postoperative pancreatic fistula. World J Gastroenterol 2013; 19(27): 4351-4355, https://doi. org/10.3748/wjg.v19.i27.4351.

18. Machado N.O. Pancreatic fistula after pancreatectomy: definitions, risk factors, preventive measures, and management - review. Int J Surg Oncol 2012; 2012: 60247, https://doi.org/10.1155/2012/602478.

19. Zaporozhchenko B.S., Kachanov V.N., Zubkov O.B., Borodaev I.E., Gorbunov A.A., Shevchenko V.G. Different variants of pancreatodigestive anastomoses during pancreatoduodenal resections. Vestnik neotlozhnoy $i$ vosstanovitel'noy meditsiny 2012; 13(2): 270-272.

20. Kasatkin V.F. Improvement of immediate results of pancreatoduodenal resection for periampullary cancer. Khirurgiya. Zhurnal im. N.I. Pirogova 2008; 10: 10-16.

21. Suzuki Y., Fujino Y., Tanioka Y., Hiraoka K., Takada M., Ajiki T., Takeyama Y., Ku Y., Kuroda Y. Selection of pancreaticojejunostomy techniques according to pancreatic texture and duct size. Arch Surg 2002; 137(9): 1044-10478, https://doi.org/10.1001/archsurg.137.9.1044.

22. Chernyavskiy A.A., Lavrov N.A., Strazhnov A.V., Penin S.V. Pancreatic resections in operations about gastric cancer. Vestnik khirurgicheskoy gastroenterologii 2013; 3: 4-13.

23. Kriger A.G., Kubyshkin V.A., Karmazanovskii G.G., Svitina K.A., Kochatkov A.V., Berelavichus S.V., Kozlov I.A., Korolev S.V., Gorin D.S. The postoperative pancreatitis after the pancreatic surgery. Khirurgiya. Zhurnal im. N.I. Pirogova 2012; 4: 14-19. 